\title{
Thyroid Cancer in Ecuador, a 16 years population-based analysis (2001-2016)
}

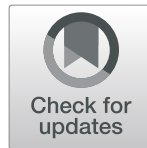

\author{
Jorge Salazar-Vega ${ }^{1,2}$, Esteban Ortiz-Prado ${ }^{1,3^{*}}$ (D), Paola Solis-Pazmino ${ }^{4}$, Lenin Gómez-Barreno ${ }^{1}$, \\ Katherine Simbaña-Rivera', Aquiles R. Henriquez-Trujillo ${ }^{1}$, Juan P. Brito ${ }^{5}$, Theofilos Toulkeridis ${ }^{6}$ and \\ Marco Coral-Almeida ${ }^{1}$
}

\begin{abstract}
Background: Thyroid cancer is the most frequent endocrine neoplasia worldwide. Information from Andean countries is scarce. In Ecuador there is no reports available of the epidemiology of this type of cancer. The aim of this study is to present the epidemiology and the burden of disease of thyroid cancer.

Methods: This is a cross-sectional population-based analysis of thyroid cancer epidemiology in Ecuador from 2001 to 2016. The variables studied were the overall mortality rate, socio-demographics characteristics of the hospitalized patients, geographical trends and the burden of thyroid cancer in Ecuador. All the data was obtained from the official records reported by the Ministry of Public Health's and retrieved from the public databases of the Vital Statistics Deaths and Births Databases and the National Institute of Census and Statistics (INEC).

Results: In Ecuador, over a period of 16 years from 2001 to 2016 a total of 23,632 hospital admissions were reported, which caused 1539 deaths due thyroid cancer. Data demonstrated an annual mean of 1477 cases, which caused 96 deaths per year in average. The annual incidence fluctuated from 3 in 2001 to 22 in 2016 per 100,000 inhabitants. Women were 5 times more likely than men to have thyroid cancer. The average length of stay for both sexes were 4 days. The mortality attributable to thyroid cancer represent less than $0.3 \%$ of all cancer deaths.

Conclusion: Ecuador has one of the highest rates of thyroid cancer in Latin America, ranking first among women in Latin America. Although this cancer is frequent, mortality rate is relatively low. As this is the first national report of thyroid cancer in the country, a further analysis of the pathological variants and the grading of this neoplasia is needed.
\end{abstract}

Keywords: Thyroid Cancer, Epidemiology, Ecuador, Latin America, DALY, YYL

\section{Background}

A rapid increase in the incidence of thyroid cancer has been reported in several countries across the world showing significant geographic differences. South Korea, Italy and United States experienced relatively high incidence of thyroid cancer, while some Northern European countries have observed low incidence and minimal increase [1-3]. The underlying causes of this geographic variation remain unknown but difference in health care

\footnotetext{
* Correspondence: e.ortizprado@gmail.com

'OneHealth Research Group, Faculty of Medicine, Universidad de las

Americas, Calle de los Colimes y Avenida De los Granados, 170137 Quito, Ecuador

${ }^{3}$ Department of Cell Biology, Physiology and Immunology, Universidad de Barcelona, Barcelona, Spain

Full list of author information is available at the end of the article
}

systems, access to care, cancer screening practices have been proposed as possible reasons for these discrepancies [1].

One geographic area where thyroid cancer epidemiology has been underreported is South America. A few countries such as Brazil $(1.8 / 100,000)$, Colombia (2.1/ $100,000)$ or Chile $(7.8 / 100,000)$ have reported data about their incidence of thyroid cancer, however, the majority of Latin-American countries such as Ecuador, Peru, Bolivia or Paraguay have not reported thyroid cancer trends, incidences or any epidemiological data in the last decade [4-7]. Understanding different trends and epidemiological variability among Latin American countries will offer more information to help us understand the

(c) The Author(s). 2019 Open Access This article is distributed under the terms of the Creative Commons Attribution 4.0 International License (http://creativecommons.org/licenses/by/4.0/), which permits unrestricted use, distribution, and reproduction in any medium, provided you give appropriate credit to the original author(s) and the source, provide a link to the Creative Commons license, and indicate if changes were made. The Creative Commons Public Domain Dedication waiver (http://creativecommons.org/publicdomain/zero/1.0/) applies to the data made available in this article, unless otherwise stated. 
reasons behind the increasing rates of thyroid cancer worldwide.

The purpose of this study is to describe the incidence and mortality patterns of thyroid cancer in Ecuador from 2001 to 2016, as well as the overall economic impact of thyroid cancer in the country.

\section{Methodology}

\section{Study population}

This is a national-wide cross-sectional design including all the reported cases of thyroid cancer (C-73) in Ecuador in a 16 years period (2001-2016). All the information comes from the public repositories of mortality and hospital discharges obtained from the National Institute of Census and Statistics (INEC).

\section{Data sources}

Information was retrieved from the hospital discharge database in the last 16 years of available data. The website http://www.ecuadorencifras.gob.ec/estadisticas-decamas-y-egresos-hospitalarios-bases-de-datos/ contains full set of records in a yearly manner.

Thyroid cancer (C-73) was analyze by year with a resolution that included date of discharge by month, cantons (224) and provinces (24) of residence as well as the institutions where treatment was offered. The hospital discharge and the mortality databases contain individual information for demographic characteristics, data on length of stay and mortality, however, the tumor, nodes and metastasis staging (TNM) information was not available. For the burden of disease analysis, the TNM grading was assigned accordingly to the proportion of TNM cancer stage described in previous reports from the country's National Registry of Cancer published by the National Society of Fighting against Cancer. All data was analyzed by sex, age, marital status, ethnic background, province and canton of residency, educational attainment, and days of hospitalization in the last 16 years.

\section{Burden of disease}

The impact of thyroid cancer was quantify in disability adjusted life years (DALYs), following previously described methods [8]. DALY are the sum of years lived with disability (YLD) and years of life lost due to premature mortality (YLL) [9]. All the cases of thyroid cancer registered as C-73 were included. YLDs were calculated from the hospital discharges databases as the product of the number of incident cases of thyroid cancer, times the disability weight attributed to the disease in the year of diagnosis. Disability weights, described by the Global Burden of Disease 2013 study [10], were assigned accordingly to the proportion of TNM cancer stage described in previous reports from the country's National
Registry of Cancer published by the National Society of Fighting against Cancer (SOLCA) [11]. We used an average disability weight of 0.288 corresponding to diagnosis and primary treatment for stages I to III, and a disability weight of 0.451 for metastatic stage IV [10]. YLLs were estimated as the product of the number of deaths registered due to thyroid cancer and the residual life expectancy at the age of death. Life expectancy was set in 80 years for man and 82.5 for women according to the Coale Demeny model life table system.

\section{Data analysis}

The incidence and mortality rates were age-standardized using the 2010 national population census [12]. The number of cases and deaths were summarized as absolutes numbers and relative frequencies (\%). The mortality rate was calculated using the annual population at risk by ethnicity, sex, age group and the geographic location of the incidence. The calculations were completed using the IBM SPSS statistics version 24.0. Citation and retrieval of references were performed using the Zotero Open Source Software version 4.0.11. Spatial analysis was performed using the software QGIS 2.8 and the DALY calculations were performed using STATA software v14. All the graphs and maps were elaborated by the authors.

\section{Results \\ Ecuador}

From 2001 to 2016, 23,632 cases of thyroid cancer were diagnosed in Ecuador. The mean age at diagnosis was 49 years ( \pm 15 years), $80 \%$ were women, with no formal education (45\%), mainly diagnosed in urban areas (90\%), and treated under public health care system (64\%) followed by private for profit (18\%), and the private for nonprofit (13\%). Thyroid cancer was more frequently reported among mestizos (85\%), whites (7\%), indigenous (7\%) and Afro-Americans (1\%).

\section{Incidence, prevalence and mortality}

The annual incidence fluctuated from 3 in 2001 to 22 in 2016 per 100,000 inhabitants, being the annual average prevalence lower in men with 3.5 cases per 100,000 versus 16.6 cases per 100,000 in women (2001-2016). The prevalence rates present geographic variation ranging from 3 cases per 100,000 individuals in Orellana to 338 cases per 100,000 individuals in Azuay (Fig. 1).

When analyzed by cantons, the canton with highest prevalence rates was Riobamba with 435 cases per 100,000 individuals while the lowest prevalence rates was 2.3 cases per 100,000 individuals in San Lorenzo, Esmeraldas (Fig. 2).

The differences in prevalence rate change from region to region. The highlands have a prevalence rate of 122/ 

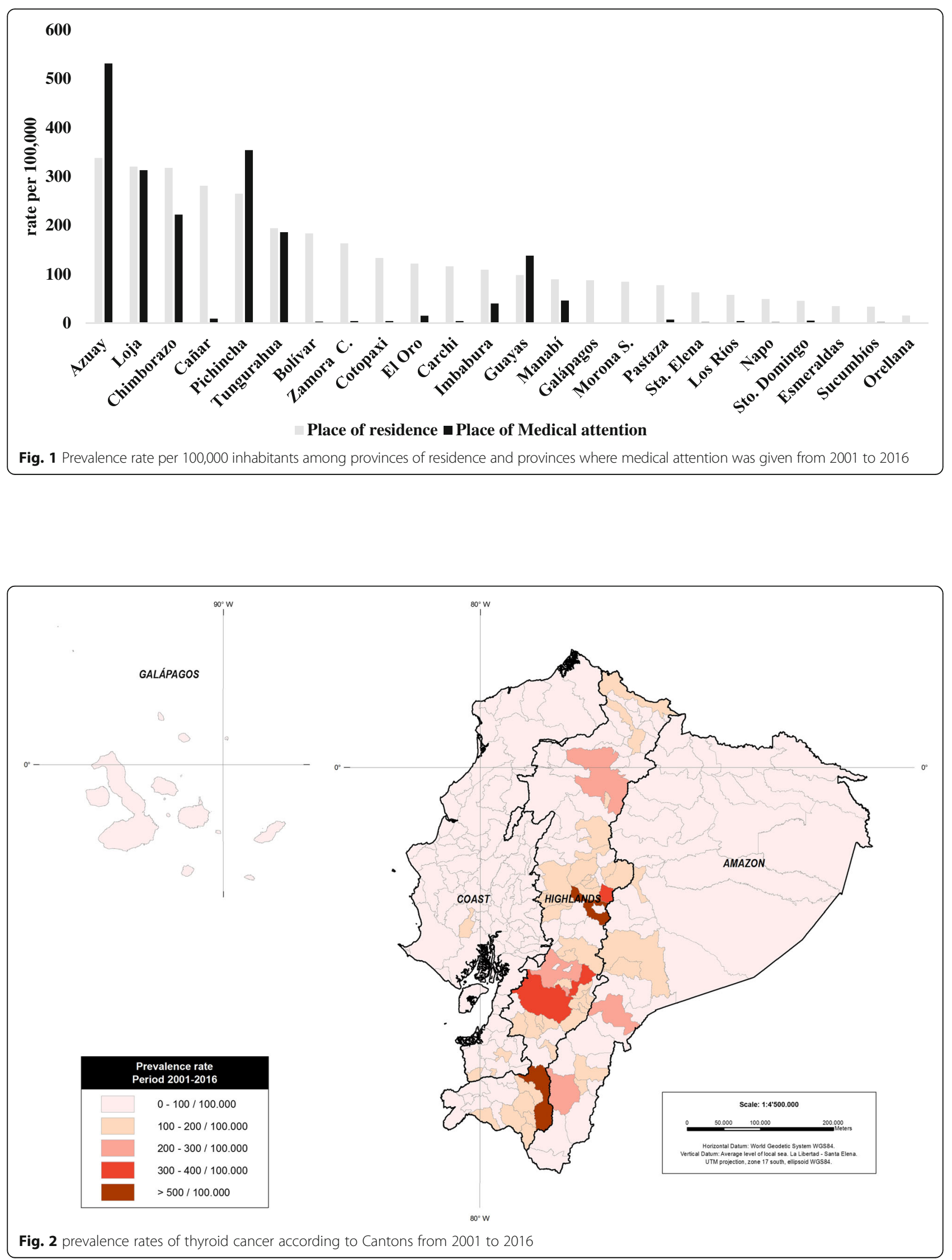
100,000, followed by the Amazonia with 47/100,000 and the Coastal region (Including the Galapagos islands) a prevalence of 46/100,000 (Fig. 2).

Thyroid cancer mortality according to death rates at all ages per 100,000 was found to be 0.36 deaths in men and 0.95 deaths in women per 100,000 with a female to male mortality of 2:1 (Figs. 3 and 4).

When analyzed by age groups, children and adolescents, mortality is $0 \%$, slightly increasing up to $0.1 \%$ in young adults (21 to 39 years old) reaching the highest mortality among elderly people with thyroid cancer, with morality incidence of 7 per 100,000 (figure 4100).

\section{Trends}

2001 to 2016 the incidence of thyroid cancer increased from 3 to 22 per 100,000 individuals, during the same time thyroid cancer mortality increased from 0.48 to 0.87 per 100,000 individuals in the overall 16 years period. The incidence trend analysis stratified by gender revealed increasing rates in women, from 4.3 to 42.2 cases per 100,000 individuals, while in men from 0.97 to 8.4 cases per 100,000 individuals (Fig. 5).

\section{DALYs and YLLs analysis}

During the period 2001-2016 in Ecuador there were 23,632 patients who were admitted to the hospital with diagnosis of thyroid cancer. In this time period 1539 deaths were attributed to thyroid cancer. These deaths are equivalent to 26,202 years of life lost due to premature mortality (Table 1 ).

\section{Discussion}

Thyroid cancer is a relatively common malignancy in Ecuador. The incidence and mortality rates had a significantly variation from 2001 to 2016. During this period, the number of cases increased almost 20 times. Our report demonstrated that in the study population the ratio women/men is 5:1.

According to global reports, the incidence and mortality of thyroid cancer in Ecuador (both male and female) exceeds the rest of countries in Latin America, and is among the highest in the world [5, 13] (Table 2). Remarkably, in older adults (>65 years) the mortality is greater than $25 \%$. We hypothesized that it might be due to comorbidities more frequents in this age.

When we refer to the group of children and adolescents, we have found that they are still relatively unaffected by thyroid cancer, representing less than $2 \%$ of the overall incidence countrywide $[2,14]$.

Over these 16 years, the significant increase of the thyroid cancer had an evident influence in the disability adjusted life years with a rise of 12.7 DALY per 100.000 depending mainly on younger adults (Table 1) $[15,16]$.

Part of the debate encloses some of the arguments that explain a higher incidence of thyroid cancer, in the last decade. Over-diagnosis in fact due to new technologies that permit early diagnosis of a greater number of small tumours that are usually clinically undetectable, but evident by radiological and diagnostic techniques like CT scan or ultrasound respectively $[13,17-20]$. In recent years in Ecuador, a better healthcare and improved (both public and

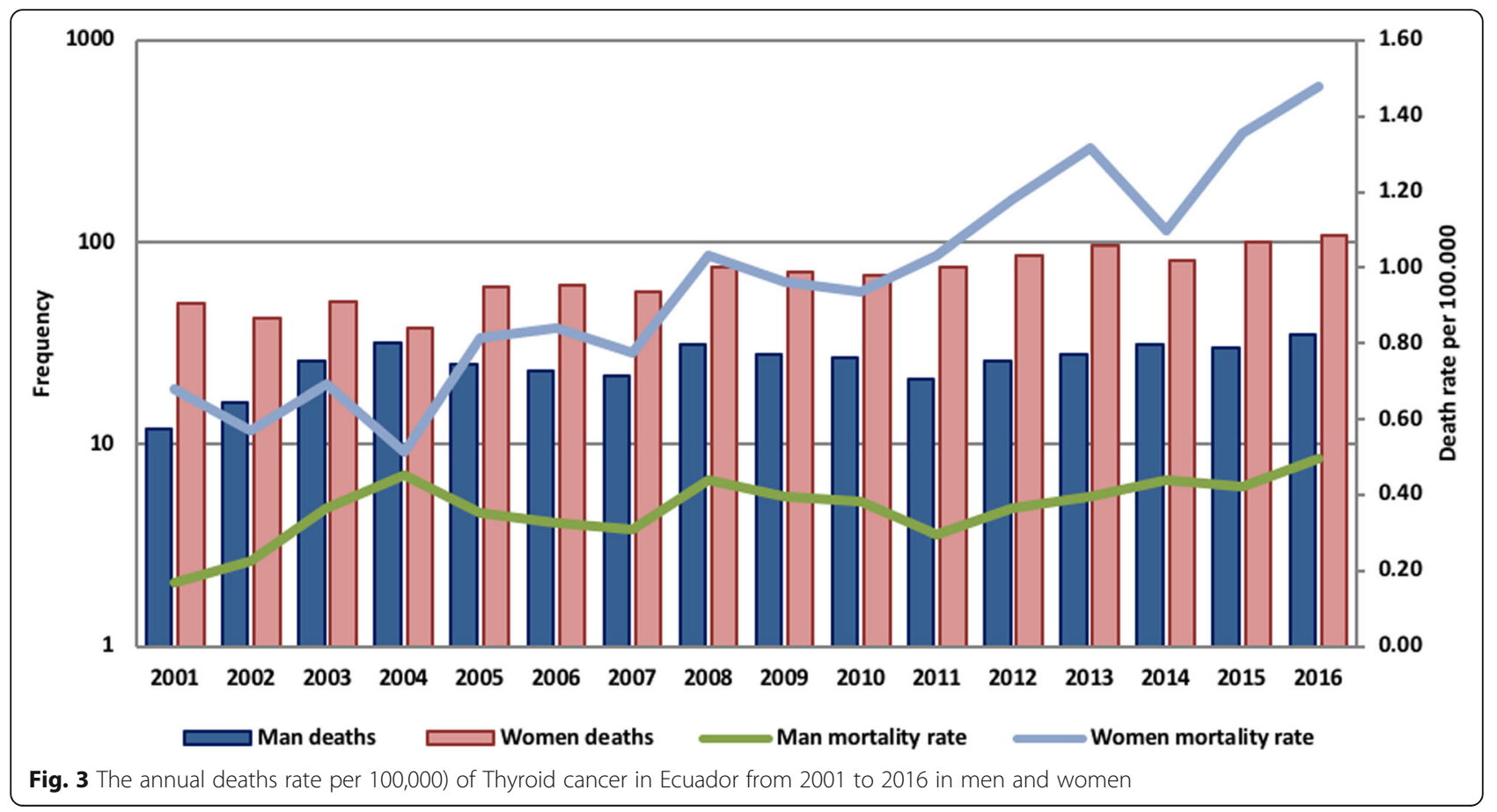




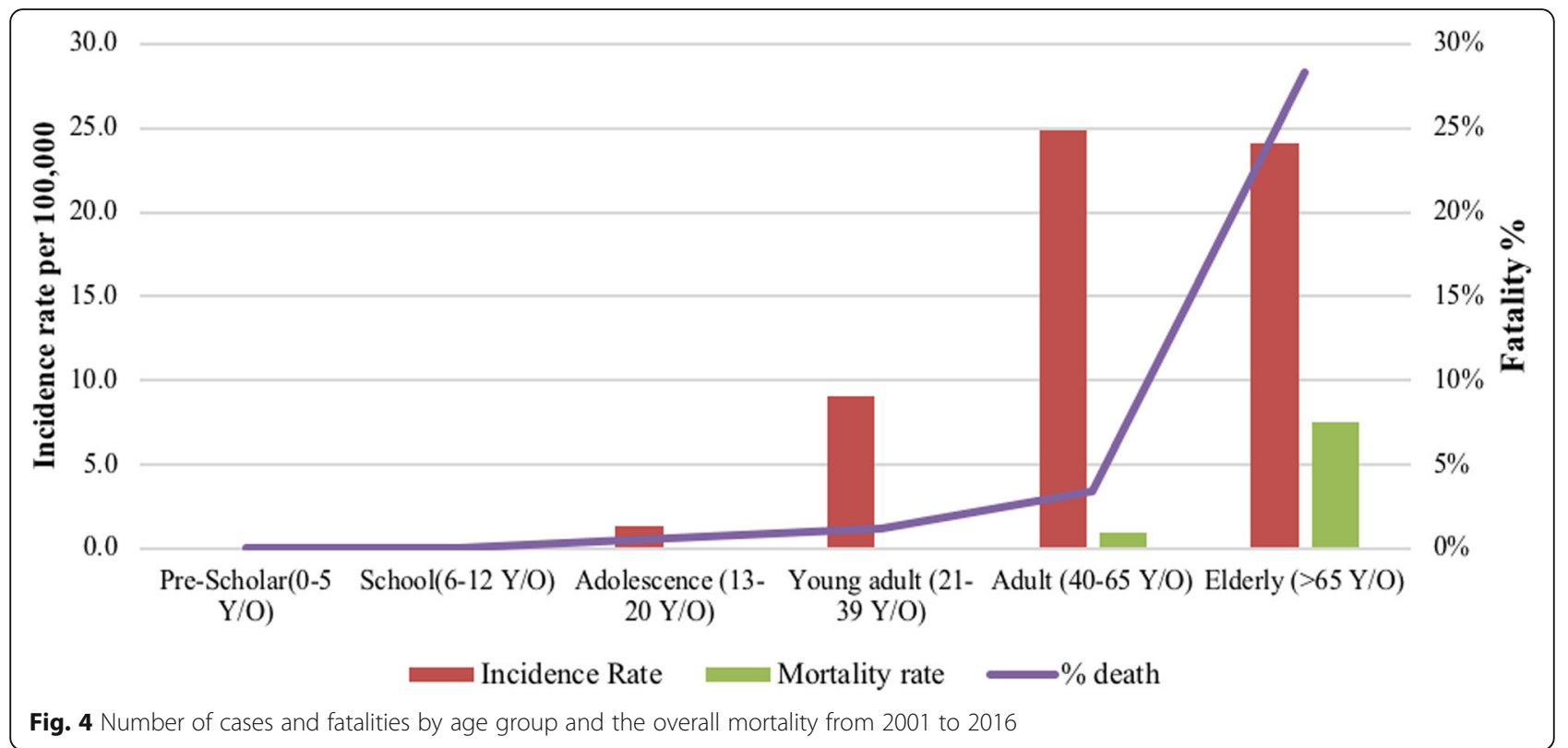

private) access might be one of the reasons related with a possible over utilization of diagnostic tools [21, 22].

The influence of other factors such as the use of radioactive drugs (i.e. iodine-123 or iodine-131) in hyperthyroid patients has never been explored in the country, however recently published studies have established a possible link between the use of radioactive iodine and some forms of thyroid cancer [23, 24].

In Ecuador like in many Latin American countries with similar standard of care and comparable health systems, information about screening test that resulted in false positives is not available. In despite of this,

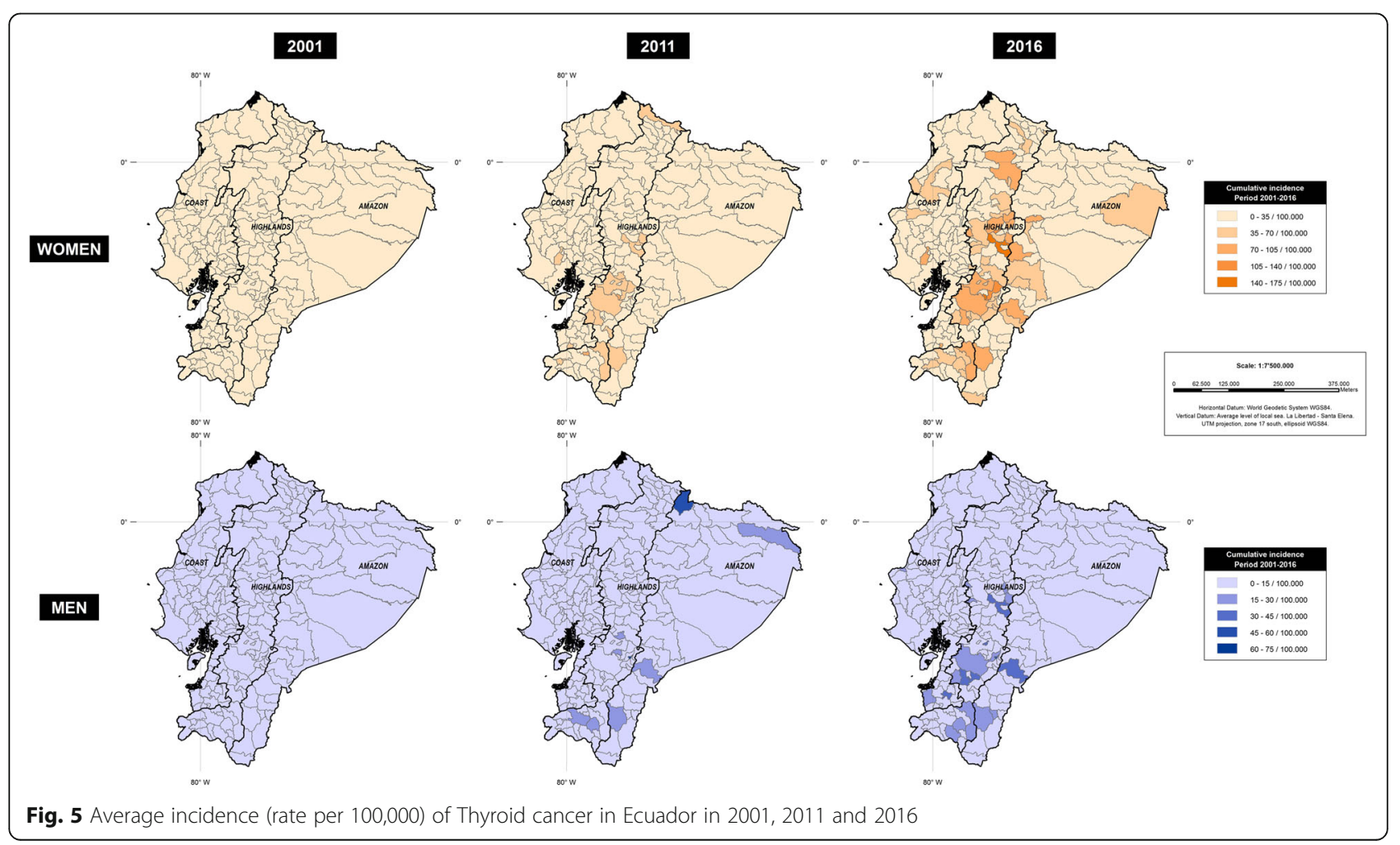


Table 1 Burden of disease estimation of Thyroid cancer (ICD-10: C-73) in Ecuador from 2001 to 2016

\begin{tabular}{lllll}
\hline Year & YLL & YLD & DALY & DALY per 100 k pop. \\
\hline 2001 & 1173 & 118 & 1291 & 10.1 \\
2002 & 1229 & 130 & 1359 & 10.4 \\
2003 & 1547 & 152 & 1699 & 12.8 \\
2004 & 1225 & 171 & 1396 & 10.3 \\
2005 & 1352 & 205 & 1557 & 11.3 \\
2006 & 1443 & 236 & 1679 & 12.0 \\
2007 & 1393 & 293 & 1685 & 11.9 \\
2008 & 1692 & 343 & 2035 & 14.1 \\
2009 & 1633 & 337 & 1971 & 13.4 \\
2010 & 1499 & 411 & 1910 & 12.7 \\
2011 & 1664 & 500 & 2164 & 14.2 \\
2012 & 1779 & 594 & 2373 & 15.3 \\
2013 & 2017 & 736 & 2754 & 17.5 \\
2014 & 1810 & 872 & 2682 & 16.7 \\
2015 & 2116 & 998 & 3115 & 19.1 \\
2016 & 2630 & 1134 & 3764 & 22.8 \\
\hline
\end{tabular}

YLL years life lost due to mortality, YLD years lived with disability, DALY disability adjusted life years

countries in other regions have reported that massive screening is related to a higher rate of thyroid cancer with no direct impact on the overall mortality [1,25-27].

Our results demonstrate that certain ethnic backgrounds have higher incidence of thyroid cancer, than others. For instance, in Ecuador the racial thyroid cancer's distribution is greater among mestizo population, maybe due to the fact that mestizos are the greater population in the country, having similar mortality rates among them [12]. There is some data reporting that thyroid cancer's survival rates might be different among populations, in example, in the United States of

Table 2 Age-standardized incidence and mortality rates (per 100,000) in Latin-America

\begin{tabular}{|c|c|c|c|c|c|c|c|}
\hline \multirow[t]{2}{*}{ Country } & \multirow[t]{2}{*}{ Period } & \multicolumn{3}{|c|}{ Incidence } & \multicolumn{3}{|c|}{ Mortality } \\
\hline & & $\mathrm{F}$ & $M$ & $\mathrm{~F}: \mathrm{M}$ & $\mathrm{F}$ & $M$ & $\mathrm{~F}: \mathrm{M}$ \\
\hline Argentina & 2003-2007 & 5.5 & 1.4 & 4 & 0.4 & 0.3 & 1.3 \\
\hline Brazil & 2003-2007 & 14.4 & 3.4 & 4.2 & 0.4 & 0.2 & 2 \\
\hline Chile & 2003-2007 & 8.2 & 1.4 & 5.7 & 0.6 & 0.4 & 1.5 \\
\hline Colombia & 2003-2007 & 10.7 & 2.5 & 4.2 & 0.8 & 0.4 & 2 \\
\hline Costa Rica & 2003-2007 & 12.6 & 2.1 & 6.1 & 0.5 & 0.4 & 1.3 \\
\hline Cuba & 2004-2007 & 7.7 & 1.5 & 5.2 & 0.4 & 0.3 & 1.3 \\
\hline Ecuador & 2003-2007 & 16 & 3.5 & 5.0 & 0.9 & 0.5 & 2.6 \\
\hline Mexico & 2006-2010 & 4.9 & 1.2 & 4 & 0.9 & 0.5 & 1.8 \\
\hline Peru & 2001-2005 & 7.5 & 1.7 & 4.4 & 0.7 & 0.3 & 2.3 \\
\hline Uruguay & 2005-2007 & 6.8 & 1.6 & 4.2 & 0.4 & 0.4 & 1 \\
\hline
\end{tabular}

America, non-Hispanic whites are less affected than the Hispanic and African-American populations [28, 29].

It is relevant to point out that $45 \%$ of patients had poor educational attainment even though more than $90 \%$ of the cases were diagnoses among urban dwellers. These socioeconomic conditions are similar to those reported in other studies and might influenced the detection patterns (and therefore incidence) of thyroid cancer in the country [30-33].

The majority of patients with thyroid cancer, reside within the highland's region. The provinces of Azuay, Loja and Chimborazo have the highest number of affected. The canton with the highest incidence was Riobamba in the province of Chimborazo. The results of our study show that, on average, the prevalence rates are higher in the mountainous regions of Ecuador (averaged elevation $2358 \mathrm{~m}$ ) compared to those of the Amazon region (averaged elevation $731 \mathrm{~m}$ ) and the coast (averaged elevation $93 \mathrm{~m}$ ). The association between elevation and thyroid cancer was not profoundly explored in our investigation, however, some reports suggest that a link between extreme geographies and thyroid cancer might have some biological plausibility [34-36].

The role of iodine supplementation and the risk of developing hypothyroidism, goitre and cretinism was explored in Ecuador and Peru during the 60's [37, 38]. The quality of the soils and the lack of iodine was established as one of the main reasons of the greater incidence of goitre among high altitude dwellers when compared to their coastal peers [37]. An efficient and worldwide salt iodization campaign reduced the trends of goitre and hypothyroidism, nevertheless the quality of the soils, neither the average intake of iodine has been ever explored in Ecuador.

It could be speculated that after decades of high iodine intake, a paradoxical effect might have occurred in some parts of Ecuador, leading to higher risk of developing thyroid tumours [39-41]. Reports from the past have shown that overstimulating the thyroid gland with iodine-rich diets and high iodine intake might be related with an increased risk of developing thyroid tumours in animal models [42, 43]. In humans, some of the studies available reporting a possible association between iodine intake and thyroid cancer have led to controversial results $[39,40,44-46]$.

\section{Limitations}

The main limitation of this type of analysis is the lack of individual's data concerning the tumor stratification and the risk factors attributed to developing thyroid cancer. Another major limitation is that the current study cannot separate thyroid cancer by histological subtype. The use of nationwide secondary data could lead to information bias, particularly relevant for the validity of the 
confirmatory diagnosis of thyroid cancer and the lack of country guidelines for accurate diagnosis.

\section{Conclusion}

Describing the local epidemiology of thyroid cancer is an important step in order to improve health access and to promote evidence-based health public policies. This report is the first in Ecuador analyzing the epidemiology and burden of diseases of thyroid cancer with a cantonal resolution. The results confirm that Ecuador has the highest rates in Latin America of this type of neoplasia, which follows a continues increment in the incidence of thyroid cancer, without changing mortality in the same rate as the diagnosis does. A further analysis is needed in order to investigate the risk factors associated with higher risk of developing this type of cancer in Ecuador, especially that attributed to high altitude exposure, soil composition and iodine intake.

\section{Abbreviations \\ C-73: Thyroid cancer; DALY: Disability adjusted life years; GCP: Good clinical practices; INEC: National Institute of Census and Statistics; TNM: Tumor, Nodes and Metastasis Staging System; YLD: years lived with disability; YLL: Years of life lost}

\section{Acknowledgements}

The authors wish to thank Rebeca Bravo who was very keen in editing our maps for this publication.

\section{Funding}

This work did not receive financial support of any kind.

\section{Availability of data and materials}

All the information used for this analysis can be found in the following website http://www.ecuadorencifras.gob.ec/estadisticas-de-camas-y-egresoshospitalarios-bases-de-datos/ and contains a full set of records in a yearly manner from 2001 to 2016.

\section{Authors' contributions \\ JSV and PSP were responsible of the conceptualization of the study and both participate in the drafting of the background and discussion section. They also performed a complete revision and approval of the final draft of the manuscript. EOP was responsible for the full conceptualization, the methodology and the data collection of the study. He was in charge of drafting the document in all of the stages. He performed the epidemiological and statistical analysis. He is fully responsible for this work as the corresponding author. LGB and KSR were fully responsible for acquiring the data in XLS format and transformed into CVS format. They also collaborate in the elaboration of Table 1 and the resolution of the editor's comments during the peer review process. AHT and MC were fully responsible for the DALY and burden of disease analysis while providing critical revisions of the rest of the analysis. JPB added a very important point of view regarding mortality rates and incidence of thyroid cancer, He also critically reviewed the entire manuscript and produced several comments prior to submission. TT helped us with the geographical and regional data analysis as with the conceptualization of the maps.}

\section{Ethics approval and consent to participate}

According to the local and international regulation, this project did no required ethical approval. All the data comes from secondary unidentifiable records. The Hospital discharge database is available through the National Institute of Statistic and Census of Ecuador (INEC) portal.

\section{Consent for publication}

Not Applicable.

\section{Competing interests}

The authors declare that they have no competing interests.

\section{Publisher's Note}

Springer Nature remains neutral with regard to jurisdictional claims in published maps and institutional affiliations.

\section{Author details}

${ }^{1}$ OneHealth Research Group, Faculty of Medicine, Universidad de las Americas, Calle de los Colimes y Avenida De los Granados, 170137 Quito Ecuador. ${ }^{2}$ Endocrinology Department, Hospital Eugenio Espejo, Quito, Ecuador. ${ }^{3}$ Department of Cell Biology, Physiology and Immunology, Universidad de Barcelona, Barcelona, Spain. ${ }^{4}$ Faculty of Medicine, Universidad Central del Ecuador, Quito, Ecuador. ${ }^{5}$ Division of Endocrinology, Diabetes, Metabolism and Nutrition, Department of Medicine and the Knowledge and Evaluation Research Unit, Mayo Clinic, Rochester, MN, USA. ${ }^{6}$ Escuela Superior Politecnica del Ejercito, Sangolqui, Ecuador.

Received: 11 September 2018 Accepted: 18 March 2019

Published online: 02 April 2019

\section{References}

1. Park S, Oh C-M, Cho H, Lee JY, Jung K-W, Jun JK, et al. Association between screening and the thyroid cancer "epidemic" in South Korea: evidence from a nationwide study. BMJ. 2016;355:15745.

2. Lim H, Devesa SS, Sosa JA, Check D, Kitahara CM. Trends in thyroid Cancer incidence and mortality in the United States, 1974-2013. JAMA. 2017:317:1338.

3. Dal Maso L, Lise M, Zambon P, Falcini F, Crocetti E, Serraino D, et al. Incidence of thyroid cancer in Italy, 1991-2005: time trends and ageperiod-cohort effects. Ann Oncol. 2010;22:957-63.

4. Carrasquilla-Sotomayor M, Alvis-Zakzuk NJ, de la Rosa FG, Zakzuk JA, Figueroa RM, Machado PM, et al. Cost and effectiveness of the use of Sorafenib in differentiated thyroid Cancer. Value Health. 2017;20:A876,

5. La Vecchia C, Malvezzi M, Bosetti C, Garavello W, Bertuccio P, Levi F, et al. Thyroid cancer mortality and incidence: a global overview. Int J Cancer. 2015:136:2187-95.

6. Sapunar J, Muñoz S, Roa JC. Epidemiología del cáncer de tiroides en Chile: Resultados del estudio INCATIR. Rev Médica Chile. 2014:142:1099-105.

7. Veiga LHS, Neta G, Aschebrook-Kilfoy B, Ron E, Devesa SS. Thyroid Cancer incidence patterns in Sao Paulo, Brazil, and the U.S. SEER program, 19972008. Thyroid. 2013;23:748-57.

8. Murray CJ, Vos T, Lozano R, Naghavi M, Flaxman AD, Michaud C, et al. Disability-adjusted life years (DALYs) for 291 diseases and injuries in 21 regions, 1990-2010: a systematic analysis for the global burden of disease study 2010. Lancet. 2013;380:2197-223.

9. Devleesschauwer B, Mc Donald S, Haagsma J, Praet N, Havelaar A, Speybroeck N. The DALY Calculator-A GUI for stochastic DALY calculation in $\mathrm{R} ; 2014$

10. Salomon JA, Haagsma JA, Davis A, de Noordhout CM, Polinder S, Havelaar $\mathrm{AH}$, et al. Disability weights for the global burden of disease 2013 study. Lancet Glob Health. 2015:3:e712-23.

11. SOLCA. Registro Nacional de Tumores. Epidemiología del Cancer en Quito 2006-2010. 2014.

12. INEC. VII Censo de Población y VI de Vivienda 2010. 2010.

13. Sierra MS, Soerjomataram I, Forman D. Thyroid cancer burden in central and South America. Cancer Epidemiol. 2016:44:S150-7.

14. Cordioli MICV, Canalli MHBS, Coral MHC. Increase incidence of thyroid cancer in Florianopolis, Brazil: comparative study of diagnosed cases in 2000 and 2005. Arq Bras Endocrinol Metabol. 2009;53:453-60.

15. Barr RD, Ferrari A, Ries L, Whelan J, Bleyer WA. Cancer in adolescents and young adults. JAMA Pediatr. 2016;170:495.

16. Brown RL, de Souza JA, Cohen EE. Thyroid cancer: burden of illness and management of disease. J Cancer. 2011;2:193.

17. Brito JP, Yarur AJ, Prokop LJ, Mclver B, Murad MH, Montori VM. Prevalence of thyroid Cancer in multinodular goiter versus single nodule: a systematic review and meta-analysis. Thyroid. 2013;23:449-55.

18. Brito JP, Davies L. Is there really an increased incidence of thyroid cancer? Curr Opin Endocrinol Diabetes Obes. 2014;21:405-8.

19. Midorikawa S, Ohtsuru A, Murakami M, Takahashi H, Suzuki S, Matsuzuka T, et al. Comparative analysis of the growth pattern of thyroid Cancer in 
young patients screened by ultrasonography in Japan after a nuclear accident. JAMA Otolaryngol Neck Surg. 2017.

20. Carlberg M, Hedendahl L, Ahonen M, Koppel T, Hardell L. Increasing incidence of thyroid cancer in the Nordic countries with main focus on Swedish data. BMC Cancer. 2016;16:426.

21. Espinosa V, de la Torre D, Acuña C, Cadena C. Los recursos humanos en salud según el nuevo modelo de atención en Ecuador. 2017. http://iris. paho.org/xmlui/handle/123456789/34057. Accessed 13 June 2017.

22. Ortiz-Prado E, Ponce-Zea J, Espin E, Ramirez D, Stewart-Ibarra AM, Cornejo León F. Analysis of health and drug access associated with the purchasing power of the Ecuadorian population. Rev Panam Salud Pública Pan Am J Public Health. 2015.

23. Holm L-E, Hall P, Wiklund K, Lundell G, Berg G, Bjelkengren G, et al. Cancer risk after iodine-131 therapy for hyperthyroidism. JNCI J Natl Cancer Inst. 1991:83:1072-7.

24. Metso S, Auvinen A, Huhtala H, Salmi J, Oksala H, Jaatinen P. Increased cancer incidence after radioiodine treatment for hyperthyroidism. Cancer Interdiscip Int J Am Cancer Soc. 2007;109:1972-9.

25. Zevallos JP, Hartman CM, Kramer JR, Sturgis EM, Chiao EY. Increased thyroid cancer incidence corresponds to increased use of thyroid ultrasound and fine-needle aspiration: a study of the veterans affairs health care system. Cancer. 2015;121:741-6.

26. Ahn HS, Welch HG. South Korea's thyroid-cancer "epidemic" - turning the tide. N Engl J Med. 2015;373:2389-90.

27. Vaccarella S, Franceschi S, Bray F, Wild CP, Plummer M, Dal Maso L. Worldwide thyroid-cancer epidemic? The increasing impact of overdiagnosis. N Engl J Med. 2016;375:614-7.

28. Aschebrook-Kilfoy B, Kaplan EL, Chiu BC-H, Angelos P, Grogan RH. The acceleration in papillary thyroid Cancer incidence rates is similar among racial and ethnic groups in the United States. Ann Surg Oncol. 2013;20: 2746-53.

29. Johnston LE, Tran Cao HS, Chang DC, Bouvet M. Sociodemographic predictors of survival in differentiated thyroid Cancer: results from the SEER database. ISRN Endocrinol. 2012;2012:384707.

30. Guay B, Johnson-Obaseki S, McDonald JT, Connell C, Corsten M. Incidence of differentiated thyroid cancer by socioeconomic status and urban residence: Canada 1991-2006. Thyroid Off J Am Thyroid Assoc. 2014:24:552-5.

31. Li N, Du XL, Reitzel $L R, X u L$, Sturgis EM. Impact of enhanced detection on the increase in thyroid Cancer incidence in the United States: review of incidence trends by socioeconomic status within the surveillance, epidemiology, and end results registry, 1980-2008. Thyroid. 2013;23:103-10.

32. Park SH, Lee B, Lee $\mathrm{S}$, Choi E, Choi EB, Yoo J, et al. A qualitative study of women's views on overdiagnosis and screening for thyroid cancer in Korea. BMC Cancer. 2015;15:1-8.

33. Reitzel LR, Nguyen N, Li N, Xu L, Regan SD, Sturgis EM. Trends in thyroid cancer incidence in Texas from 1995 to 2008 by socioeconomic status and race/ethnicity. Thyroid Off J Am Thyroid Assoc. 2014;24:556-67.

34. Karkoobi Y, Moradi G, Sharifi P, Ghafoori S. Assessment of thyroid cancer risk factors in Kurdistan province. Sci J Kurd Univ Med Sci. 2018;23:10-8.

35. Bonafede M, Marinaccio A, Asta F, Schifano P, Michelozzi P, Vecchi S. The association between extreme weather conditions and work-related injuries and diseases. A systematic review of epidemiological studies. Ann Ist Super Sanita. 2016;52:357-67.

36. Sharma A, Verma HK, Joshi S, Panwar MS, Mandal CC. A link between cold environment and cancer. Tumor Biol. 2015;36:5953-64.

37. Fierro-Benítez R, Penafiel W, De Groot L, Ramirez I. Endemic goiter and endemic cretinism in the Andean region. N Engl J Med. 1969;280:296-302.

38. Pretell EA, Moncloa F, Salinas R, Guerra-García R, Kawano A, Gutiérrez L, et al. Endemic goiter in rural Peru: effect of iodized oil on prevalence and size of goiter and on thyroid iodine metabolism in known endemic goitrous populations. Endem Goiter Wash DC PAHO. 1969:419-37.

39. Knobel M, Medeiros-Neto G. Relevance of iodine intake as a reputed predisposing factor for thyroid cancer. Arq Bras Endocrinol Metabol. 2007; 51:701-12.

40. Guan H, Ji M, Bao R, Yu H, Wang Y, Hou P, et al. Association of high iodine intake with the T1799A BRAF mutation in papillary thyroid cancer. J Clin Endocrinol Metab. 2009;94:1612-7.

41. Zimmermann MB, Galetti V. lodine intake as a risk factor for thyroid cancer: a comprehensive review of animal and human studies. Thyroid Res. 2015;8:8.
42. Axelrad AA, Leblond CP. Induction of thyroid tumors in rats by a low iodine diet. Cancer. 1955:8:339-67.

43. Isler $\mathrm{H}$, Leblond $\mathrm{CP}$, Axelrad AA. Influence of age and of iodine intake on the production of thyroid tumors in the rat. J Natl Cancer Inst. 1958;21: 1065-81.

44. Teng $W$, Shan $Z$, Teng $X$, Guan $H$, Li Y, Teng D, et al. Effect of iodine intake on thyroid diseases in China. N Engl J Med. 2006;354:2783-93.

45. Belfiore A, La Rosa GL, La Porta GA, Giuffrida D, Milazzo G, Lupo L, et al. Cancer risk in patients with cold thyroid nodules: relevance of iodine intake, sex, age, and multinodularity. Am J Med. 1992;93:363-9.

46. Harach HR, Escalante DA, Oňativia A, Outes JL, Day ES, Williams ED. Thyroid carcinoma and thyroiditis in an endemic goitre region before and after iodine prophylaxis. Acta Endocrinol. 1985;108:55-60.
Ready to submit your research? Choose BMC and benefit from:

- fast, convenient online submission

- thorough peer review by experienced researchers in your field

- rapid publication on acceptance

- support for research data, including large and complex data types

- gold Open Access which fosters wider collaboration and increased citations

- maximum visibility for your research: over $100 \mathrm{M}$ website views per year

At BMC, research is always in progress.

Learn more biomedcentral.com/submissions 